\title{
Several Simple Mathematical Models for the Bending Actuation of a Single-Layer Polypyrrole Actuator
}

\author{
Shuai Zhang and Xiaoxia Jiang* \\ School of mechanical engineering, Ningxia University, Helanshan West Road 489, Yinchuan, China \\ ${ }^{*}$ Corresponding author
}

\begin{abstract}
Several simple mathematical models are developed in this paper, which are used to describe the bending actuation of a single layer polypyrrole actuator, especially for the tip deflection. All the results are compared with the experimental result which was gotten in previous research. The Comparison result shows that the bending actuation of a single layer polypyrrole actuator can be describe by different simple functions. In these models, the third order polynomial model is most close to the experimental result and can be used for further works.
\end{abstract}

Keywords-polypyrrole actuator; single-layer; bending actuation; mathematical models

\section{INTRODUCTION}

Polypyrrole (PPy) is a widely used conducting polymer, it can be used for various actuators and sensors [1,2]. Doping and dedoping of counter ions during a redox reaction will cause a volume change which will be applied for actuators [3]. Bending actuation can be rarely found in a very thin single-layer film [4], but usually happens in a bi-layer or tri-layer actuator because of the different strain generate from each layer. A double layer bending actuator works because of the swelling of the polymer layer. A tri-layer bending actuator works under the different movement of the outer two polymer layers. It is a very unique phenomenon that a single-layer thin film can be bent. This phenomenon is due to the different surface situations of solution and electrode sides of the films. Figure I shows the difference between two sides [5]. A mathematical model is needed to describe the bending actuation (especially for the tip deflection) for the further research

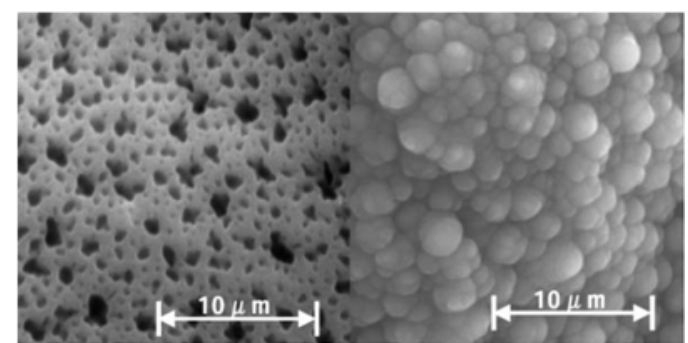

FIGURE I. SEM PHOTOGRAPHS OF TFSI-DOPED PPY FILM PREPARED ON PT ELECTRODE; ELECTRODE SIDE (LEFT) AND SOLUTION SIDE (RIGHT)

\section{EQUATION FOR VOLUME CHANGE}

There are lots of factors can affect the actuation of conductive polymer. Different ions will cause different actuations when other conditions are the same. For the same ion, higher driven voltage will operate larger actuation strain.
Besides, the concentrations of the solution and the solvent type also have different effects on the actuation. In this research, the derivation of actuation equation is based on the size of ions. It is because that, the conducting polymer will give different actuation strain and stress when it working in different solutions. When different ions doped into the polymer, the change of volume is surely different. The reason for this difference is the difference between different ions (size, density, mole mass, charging amount et. al.). It is obvious that the actuation in a big size ion solution is much larger than it operated in small size ion solution. It can be expected that by this property, the conducting polymer is able to be applied in sensors to detect and distinct kinds of ions.

To derive the equation [6], the first problem is to know the size of different ions. Equation (1) shows the volume of a single ion:

$$
V_{i}=\frac{M}{N \cdot \rho}
$$

where $V_{i}$ is the volume of a single ion, $M$ mole mass of the ion, $\mathrm{N}$ is the Avogadro constant and $\rho$ is density. In our case, $\mathrm{M}$ is $280 \mathrm{~g} / \mathrm{mol}, \mathrm{N}$ is $6.02 \mathrm{E} 23 / \mathrm{mol}$ and $\rho$ is $1.57 \mathrm{~g} / \mathrm{cm} 3$. Therefore, the volume of a single TFSI- ion is $2.96 \mathrm{E}-22 \mathrm{~cm} 3$.

The maximum volume change of the film happens

$$
\Delta V=\frac{\int_{0}^{t} i(\tau) d \tau}{q} \cdot \frac{M}{N \cdot \rho}
$$

Where $\Delta \mathrm{V}$ is the volume change, $\mathrm{i}$ is the electrical current, $\mathrm{t}$ is the operation time for half period, $\mathrm{q}$ is the changing amount of a single electron $\mathrm{M}$ mole mass of the ion, $\mathrm{N}$ is the Avogadro constant and $\rho$ is density. Because the operation voltage is given $1.5 \sin (4 \mathrm{pi} * \mathrm{t})$, i depends on the resistance what can be calculate based on the conductivity measured previously $(77.9 \mathrm{~S} / \mathrm{cm})[6]$.

Based on the experiment condition, and assume that the volume change in different direction is isotropy, the length change is can be calculated.

\section{MATHEMATICAL Models AND Results}

Three mathematical models are developed in this section. They will be used to describe the bending actuation especially 
the tip deflection. The bending configuration is shown in Figure II.

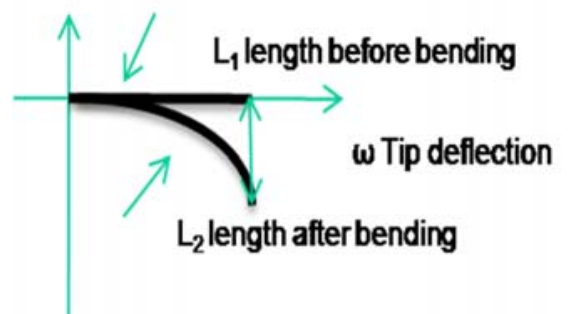

FIGURE II. SCHEMATIC DIAGRAM FOR BENDING CONFIGURATION OF A SINGLE LAYER FILM

Mathematical models:

(1) Exponential model

$$
y=3 a-4 a e^{x}+a e^{2 x}(\alpha=0.0514)
$$

(2) Polynomial model (second order)

$$
y=\operatorname{ax}^{2}(\alpha=4.743)
$$

(3) Polynomial model (third order)

$$
y=\operatorname{ax}^{3}(\alpha=237.7)
$$

A previous experiment has done to investigate the bending behavior of the single-layer PPy actuator and the tip deflection was gotten $1.9 \mathrm{~mm}$ [7]. Comparison was done in figure III and table I.

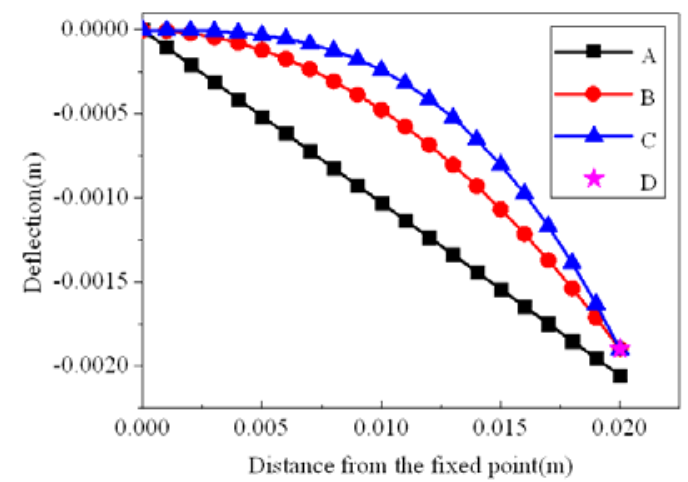

FIGURE III. FIGURE III RESULTS FROM THE MODELS COMPARED WITH THE EXPERIMENTAL RESULT (A: EXPONENTIAL MODEL; B: POLYNOMIAL MODEL (SECOND ORDER); C: POLYNOMIAL MODEL (THIRD ORDER); D: EXPERIMENTAL RESULT)

TABLE I. TABLE OF TIP DEFLECTIONS FOR DIFFERENT MODELS

\begin{tabular}{|l|c|c|c|}
\hline \multicolumn{1}{|c|}{ Model type } & $\begin{array}{c}\text { Tip } \\
\text { Deflection(mm) }\end{array}$ & $\begin{array}{c}\text { Experiment } \\
\text { result(mm) }\end{array}$ & Error \\
\hline $\begin{array}{l}\text { Exponential } \\
\text { model }\end{array}$ & 2.054 & & $8.1 \%$ \\
\hline $\begin{array}{l}\text { Polynomial model } \\
\text { (second order) }\end{array}$ & 1.8972 & \multirow{2}{*}{1.9} & $0.14 \%$ \\
\cline { 1 - 2 } $\begin{array}{l}\text { Polynomial model } \\
\text { (third order) }\end{array}$ & 1.9016 & & $0.08 \%$ \\
\hline
\end{tabular}

\section{CONCLUSIONS}

Three mathematical models are developed in this paper and compared with the experimental results. The comparison result suggest that all the models can describe the bending actuation and the third order polynomial model is most close to the experimental result for the tip deflection.

\section{ACKNOWLEDGMENT}

This research was supported by Ningxia Natural Science Foundation (NZ13003) and Startup Foundation for Doctors of Ningxia University

\section{REFERENCES}

[1] J. M. Sabsinena, J. B. Gao and H. L. Wang, "High Performance, Monolithic Polyaniline Electrochemical Aactuators," Adv. Funct. Mater., 13, pp.703, 2003

[2] Y. Bar-Cohen, "Electroactive Polymers (EAP) as Actuators for Potential Future Planetary Mechanisms," Proceedings of the NASA/DoD Conference on Evolution Hardware (EH'04), 2004

[3] P. Burgmayer and R. W. Murray, "An Ion Gate Membrane: Electrochemical Control of Ion Permeability Through a Membrane with an Embedded Electrode,” J. Am. Chem. Soc., 104, pp.6139-40, 1982

[4] G. Y. Han and G. Q. Shi, "Electrochemical Actuator Based on Ssinglelayer Polypyrrole Film," Sensors and Actuators B, 113, pp.259-64, 2006

[5] S. Hara, T. Zama, W. Takashima and K. Kaneto, "TFSI-Doped Polypyrrole Actuator with 26\% Strain,” J. Mater. Chem., 14, pp.15161517, 2004

[6] C. Kim and S. Zhang, "Mechanical and bending properties of a conductive thin single layer composite consisting of carbon nanofibers and polypyrrole" J. Mech. Sci. Tech. 28 (7) pp.2581-2585, 2014

[7] C. Kim and S. Zhang, "Bending actuation in a single-layer carbonnanofiber/polypyrrole composite film and its fabrication", J. Mech. Sci. Tech., 25 pp.1791-1796, 2011 